\title{
The Integration of Technology and Management in the Competitiveness of the United States Short Staple Yarn Manufacturing Industry
}

\author{
Suvalee T. Tangboonritruthai, ${ }^{1}$ William Oxenham, ${ }^{1}$ Nancy L. Cassill, ${ }^{1}$ and Erin D. Parrish ${ }^{2}$ \\ ${ }^{1}$ North Carolina State University, 1000 Main Campus Drive, Raleigh, NC 27695, USA \\ ${ }^{2}$ East Carolina University, Rivers Building, East Fifth Street, Greenville, NC 27858, USA \\ Correspondence should be addressed to Erin D. Parrish; parrisher@ecu.edu
}

Received 6 February 2014; Revised 15 May 2014; Accepted 22 May 2014; Published 9 June 2014

Academic Editor: Joanne Yip

Copyright (C) 2014 Suvalee T. Tangboonritruthai et al. This is an open access article distributed under the Creative Commons Attribution License, which permits unrestricted use, distribution, and reproduction in any medium, provided the original work is properly cited.

\begin{abstract}
The purpose of this research was to investigate whether a balance of technology and management could be used in order to sustain a viable United States (US) short staple yarn production industry. The methodology used in this study consisted of primary research comprising two phases. The first phase consisted of interviews with industry executives in order to find out what US yarn manufacturers think are the important factors in maintaining a competitive yarn industry. The second phase was an online survey with industry customers in order to find out why weavers and knitters buy from US manufacturers. Results reveal that US manufacturers have competitive advantages over other countries because of skill level of workforce, variety of products offered, customer relationships, innovation and technology, and product quality. In order to keep these competitive advantages, "technology" and "management" strategies should be implemented. Results also reveal the areas in which the US yarn manufacturers should focus their resources in order to stay competitive or indeed survive.
\end{abstract}

\section{Introduction}

No one who has passed from the 20th to 21st century can deny that the world today has become significantly more competitive. With the advent of instantaneous communications and relatively fast transportation systems, there is truly a global manufacturing base where products can be sourced at competitive prices. It is essential that companies embrace these changes in the business environment to ensure their growth or, in some cases, survival.

Some industry experts have recommended that, for yarn manufacturers to stay competitive in a "global" environment, quick response in the hemisphere is very important. Others have suggested that not only is quick response important but quality in products that respond tocustomer needs is also important for the company to stay competitive [1].

In order to achieve these goals, it is necessary to optimize the use of available technologies. For example, it is obvious that in yarn manufacturing two immediate prerequisites to success are high productivity and high quality; however, these must also be accompanied by correct pricing and customer service (including short delivery times and technical support). There is, however, a paramount danger in focusing on just one of the above parameters. For example, since it is evident that if one only considers advances in technology which yield significant benefits in productivity, vortex spinning would be the only choice of spinning systems used, conversely, it is clear that there are many other spinning systems which are being successfully used because their deficiencies in productivity are offset by other attributes.

Overall, differing opinions are still debated on what is really important for the yarn industry to stay competitive in the market. The top two issues are "technology," which includes the high-technology machinery and highly innovative products, and "management," which includes "how," "when," "where," and "what" to sell, be it either product or service [1]. 
Based on this, the overall research question was as follows.

What are the relative significance of "technology" and "management" and the balance of these dimensions in the long-term sustainability of the US short staple yarn manufacturing industry?

Specific research questions developed from the overall research question were as follows.

(1) What are the US short staple yarn manufacturing competitive advantages in relation to other countries?

(2) Can technology and management strategies be optimally integrated to sustain a US short staple yarn manufacturing industry?

1.1. Significance of the Research. This study is significant for three reasons. First, while many researchers have conducted studies to find out the international competitive advantage of textile and apparel as a whole industry, this study specifically focuses on short staple yarn manufacturing. This is an interesting segment of the industry that still has a major manufacturing base in the US when most areas of the industry have moved offshore. Short staple yarn also has a significant export market which is vital to the competitiveness of the US textile industry. Second, this study identifies the major key drivers that influence the success of a stable US manufacturing industry and ascertains the relative importance of these drivers. Third, the results of this study explain how "technology" and "management" can be used together to create and sustain a competitive advantage.

\section{Conceptual Framework}

2.1. The Productivity Triad. "The productivity triad provides a framework for analyzing or X-raying an economy to identify its challenges and opportunity" [2].

The concept of productivity triad captures the systemic character of change at enterprise and regional levels. The three domains of production system, business model, and skill formation are not separable and additive components but interconnected subsystems. The focus of the attention that shapes a region's capability development is on three interactive domains: business model, production system, and skill formation (Figure 1).

2.1.1. Business Model. Chesbrough [3] explains that a business model performs two important functions: it creates value and captures a portion of that value. It creates value by defining a series of activities from raw materials through to the final consumer that will yield a new product or service with value being added throughout the various activities. The business model captures value by establishing a unique resource, asset, or position within that series of activities, where the firm enjoys a competitive advantage.

Other studies mentioned that the model comprises the combined elements of "who," "what," "when," "why," "where," "how", and "how much" involved in providing customers and end users with products and services [4]. The functions of business models were developed and defined as

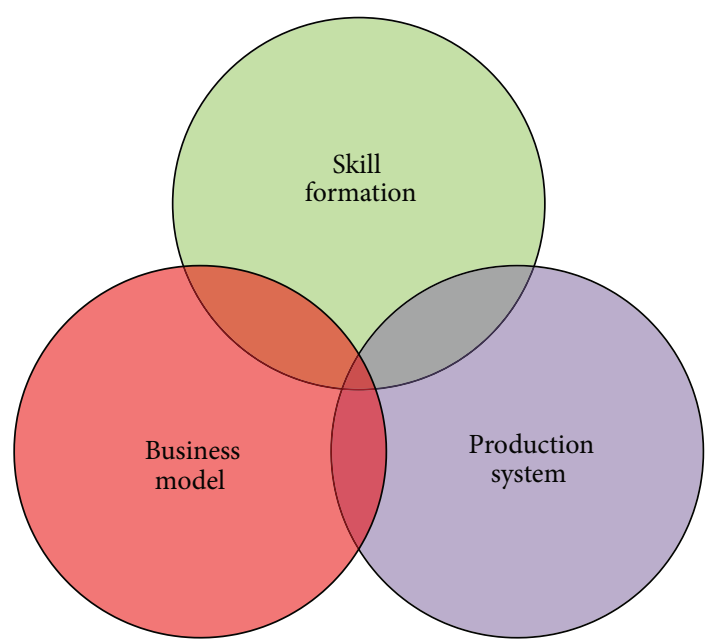

Figure 1: Diagram of the new competitive advantage. Source: Best [2].

(i) the structure of the value chain required by the firm to create the offering and determine the complementary assets needed to support the firm's position in this chain;

(ii) create the competitive strategy, and only the innovative firm will gain and hold advantage over rivals [3].

When business strategy is a long-term approach to implement a firm's business plans to achieve its business objectives, this strategy is used to facilitate gaining the competitive advantage in the market [5].

2.1.2. Production Systems. "Production capabilities are an expression of an underlying but unifying principle of production and organization. Competitive strategy and production systems are bound together" [2].

The fundamental principle of production is the development of production capabilities which includes labor productivity. Moreover, the integration of design and manufacturing is needed to compete and to keep up with rapid new product development.

2.1.3. Skill Formation. The growth process is limited by the number of scientific and engineering persons required to work for the growing companies. Best [2] stated that the condition for success depends on three conditions:

(1) characterization of the demand for specific technologic skills,

(2) investment in technical education,

(3) skill formation in the workplace.

Competitive advantage for a specified region can be built by establishing skill formation in anticipation of technology transitions. Moreover, in order to gain competitiveness with high-technology manufacturing, flexibility is needed. This flexibility depends on the ability of workforces that can learn how to use the complex new equipment quickly and to work well in groups. 
2.2. The Interconnection. The interconnection of production system, business model, and skill formation has critical implications depending on governmental policymaking. For example, when firms and regions become immovable in the low productivity triad, the government may be the only institution that can coordinate organization change in all three domains of the productivity triad.

Based on the conceptual framework, the overall research question was as follows.

Can a balance of "technology" and "management" be used to sustain a globally competitive US short staple yarn production industry?

Before this can be answered, it is important to first understand the main factors impacting the competitiveness of the yarn manufacturing industry.

2.3. Supply Chain Structure. Logistics and transportation services have become a leading area of growth in the global market. The challenge for supply chain management is the ability to accomplish delivery of the right products at the right time, all for low costs [6].

According to Kurt Salmon Associates [7], the bigger retailers have a significant impact on supply chains, especially with their increased negotiation power when purchasing large volumes. In international markets, companies are required to pay attention and deliver satisfaction to consumers while finding and maintaining specialized, reliable, and highly competitive suppliers. Since the textile chain has changed from a supply chain to a demand chain, the key success factors for this chain in the future will be joint forecasting and planning and joint inventory management as a result of cooperation between all firms in the chain [8].

2.4. Technology and Innovation. Technological change is a form of learning about how to solve specific problems in a highly differentiated and volatile environment [9]. The technology is used to reduce costs, improve quality, and increase flexibility [10]. The impact of technology changes affects the local, regional, and worldwide industry. Economic theory, historical evidence, and growth models confirm that advancing technological knowledge is the most important single factor that contributes to long-term productivity and economic growth [11].

The spinning industry has a long history in terms of technological advances. Over the past few decades, this industry has had an almost continuous flow of new developments in terms of process methods in production. The three spinning technologies (ring, rotor, and air jet spinning), with their different focus on applications, cover the entire range concerning fineness and input materials. Machine speeds have risen, and automated operations have improved production capability and increased product quality demands [12]. One of the most important technological innovations in the spinning of yarn was the introduction of open-end spinning, which combined what were formerly three separate processes into a single process using rotors instead of spindles. Spinning speeds increased at least fourfold, and labor requirements were reduced by approximately 40 percent [9].
The innovations have led to further improvements, including the increased automation and increased speed of textile operations and the consequent reduction in the number of workers needed. The drive to introduce new technologies has been stimulated mainly by the need for the production in developed countries to be cost competitive in the face of the very low labor costs in developing countries [12]. Cost reduction is not the only benefit derived from the new technologies for developed countries to gain cost competitiveness over the low labor costs in developing countries. Time saving, as the result of the automated manufacturing, also provides greater benefits for the manufacturers to respond quickly to customer demand [9].

2.5. Quality. Quality has been defined as value [13], conformance to specifications [14], fitness for use [15], and meeting and/or exceeding customer's expectations [16]. In the textile industry, the importance of quality cannot be overstated. For example, the combed cotton yarn in Canada represents high quality products that can compete over low labor cost products. Better quality products and services on a consistent basis are needed for the industry to compete internationally [10]. With the competitiveness in low-wage countries, differentiated products with high quality have made the Italian manufacturer an example of a major exception in competing with low-price products. In general, the Italian producers have pursued a strategy of product specialization. They have focused on a fashion orientation with the aim of avoiding dependence upon those types of goods most strongly affected by low-cost competition.

2.6. The Proposed Framework. After the literature review, the proposed framework (Figure 2) was developed to try to visualize the problem and was used throughout this study. The goal of this "framework" was to organize the various components into the broad categories of " $\mathrm{T}=$ technology," " $\mathrm{M}=$ management," and " $\mathrm{S}=$ skill formation." For this particular model, "technology" is defined as spinning machinery, "management" is defined as the decisions relating to what, where, and how to sell yarn, and "skill formation" is defined as the invested amount of the resources, for example, time and money.

It was believed that this approach would help to conceptualize the problem and aid in the subsequent analysis, since it should be easier with the drivers defined in broad groups. The size of the circle represents the level of importance of the components, and the distances (L1, L2) show the amount of resources invested towards "technology" and "management."

To better explain or visualize the framework dynamic, the following paragraph depicts how this framework would work in different situations (Figure 3).

In the past, the ideal model shows the balance of US yarn manufacturing with an emphasis on the importance of technology due to investment in new, high speed machinery, because the producers needed to produce yarns faster. The size of circle in " $\mathrm{T}=$ technology" is bigger than " $\mathrm{M}=$ management," and "S = skill formation" moves closer to "technology" to create balance of this model (Figure 3(a)). 

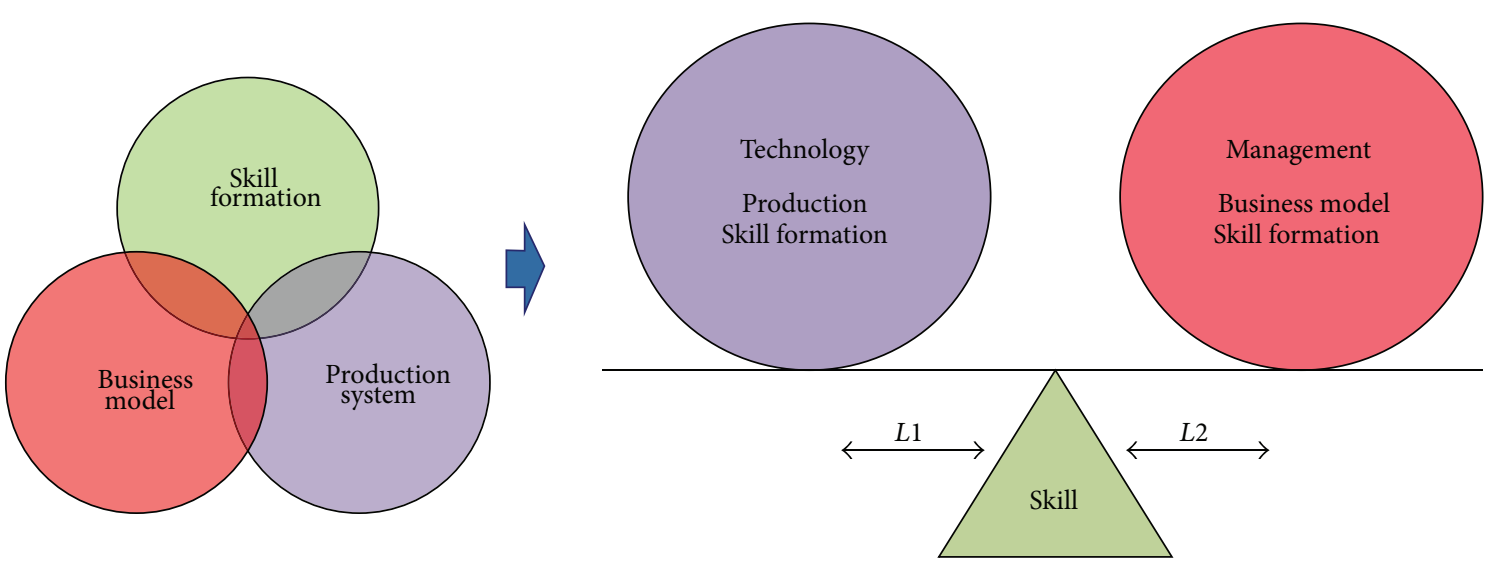

FIGURE 2: The proposed framework or "the ideal model."

When the distance L1 is shorter than the distance L2, the company is investing more towards technology resources, such as training programs for employees to have skills to work with high technology.

Another scenario shows less investment towards machinery in the United States. The ideal model (Figure 3(a)) is changed, with the importance laying more towards management and less towards technology. This situation creates an imbalance of the model shown in Figure 3(b). In order to maintain the balance, the company needs to adjust the resources invested towards management, thus restoring balance to the model (Figure 3(c)).

\section{Methodology}

In order to answer whether a balance of "technology" and "management" can be used to sustain a globally competitive yarn production industry, research was conducted in two phases: inductive and deductive. The first phase used an inductive approach and included semistructured interviews with industry executives in order to find out what US yarn manufacturers think are the important factors in maintaining a competitive yarn industry. The second phase used a deductive approach and included an online survey with industry customers to find out why weavers and knitters buy yarn from US manufacturers.

\subsection{Phase I: US Yarn Manufacturers}

3.1.1. Sample Selection. The sample of this study was US yarn spinning mills; however, the study focused only on the short staple yarn manufacturers due to its significance to the overall US textile industry. The following steps were performed in order to develop the sample list for Phase I.

Step 1. It includes identifying the company names from ReferenceUSA.com in the chosen NAICS code 313111 which represents "yarn spinning mills in the US" (population $n=$ 384).

Step 2. Determining the company location: this study selected the companies located in Alabama, North Carolina, South
Carolina, Virginia, and Georgia. It narrowed the group of companies which account for $93 \%$ of all spun yarn production in the United States (narrowed sample $n=203$ ).

Step 3. It includes narrowing the identified companies by using product/business description related to product. The product must consist of "cotton yarn or yarn from cotton blends." Then, more information about the company was gathered from many databases and websites such as Manta, Davison's Textile Blue Book, Thomas Register, Lexis@Acadamic, Hoover's Company records, and http://www.cottonsourcingusa.com/.

Moreover, this step deleted duplicate company names.

Step 4. It includes reviewing the identified companies from step 3 by experts in the yarn industry. Then, additional companies were added in the final sample list ( sample $=20$ ).

3.1.2. Instrument Development. The interview questionnaire for Phase I included both qualitative and quantitative items and was developed by the researcher based on the research objectives and the literature review. Moreover, questions from other studies [17] were modified for use in the questionnaire. It consisted of the following three sections.

Company Information. The first section of the survey for US short staple manufacturers was used to document the company's background. The responses gave an overview of respondents' area of work, size of the plant, product offered by the plant, number of spinning systems, and the age of the machinery.

Globalization. The second section of the interview questionnaire focused on globalization including rating countries in terms of the importance as customers. Respondents were also asked what, in a spinner perspective, the key drivers that are important to their customers and the choice of business strategy for the company are and to rate the importance of component in yarn costs. For this section, questions used a quantitative Likert scale rating so that results from this phase could be directly compared to the results from Phase II. Additional questions were used to find out how globalization has impacted the company. 


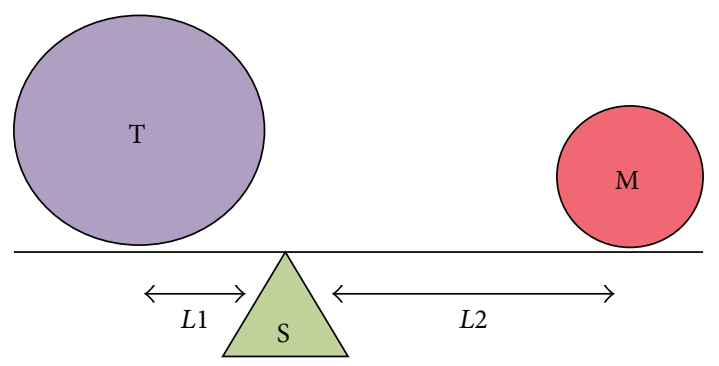

(a) Past

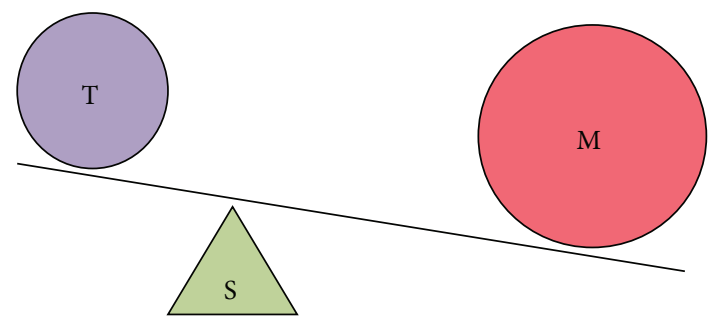

(b) Present

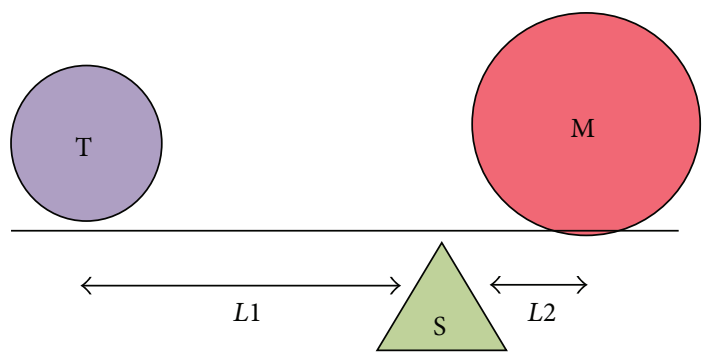

(c) Ideal

FIGURE 3: The visual graph of proposed framework.

Technology and Management. The third section of the questionnaire focused on integration of technology and management and asked the respondent's agreement regarding the impact of "technology"; the impact of "optimization in management"; and the percentage of transaction between subunits in their company. Additional questions asked the respondents to give their opinion on the integration of technology and management. This section consisted of openended questions.

After the questionnaire was field-tested with two industry experts to establish validity, the internal review board (IRB) approved the questionnaire.

3.1.3. Data Collection and Analysis. The selected US yarn manufacturers were contacted to participate in this study via email. The initial cover letter emails were sent out to the selected companies explaining the purpose of the study and requesting the company's participation in the research. Two weeks after sending out the initial cover letter, a follow-up email or phone call was made in an attempt to set up a visit or conference call. Once accepted, the semistructured interviews were conducted either in person or by telephone, and the questionnaire was used to guide the interviews, collecting both quantitative and qualitative data. The interview was used to reveal industry opinions and perceptions. However, respondents were free to add information where they deemed appropriate.

Once all the interviews were conducted, the results were analyzed based on the procedure of Yin [18] and Parrish [19]. The results were first transcribed into paragraph form. For further comparison, the information from the interviews was divided into tables. The comparison was made to determine similarities and differences regarding the integration of technology and management for the creation of long-term sustainability. Finally, the quantitative data was collected and grouped together. Mean scores were calculated so that the results from Phase I could be directly compared to the results from Phase II.

\subsection{Phase II: US Yarn Manufacturing Customers}

3.2.1. Sample Selection. Respondents in Phase I were asked to identify purchasers of short staple yarn and provided the initial sample for Phase II. Additional companies were added, but because the data for companies in other countries was limited, this study focused on companies located in Honduras, El Salvador, Columbia, Guatemala, and Dominican Republic. Furthermore, these countries represented more than 62.2 percent share of the total US export of cotton yarns in 2006 by value ( $\$$ US).

These companies' contact information was acquired from respondents in Phase I and through apparel and textiles exporters' associations' company profiles, resulting in an initial sample size of 58 . Fourteen usable responses were received, resulting in a 24 percent response rate.

3.2.2. Instrument Development. The survey for Phase II was quantitative and developed by the researcher based on the research objectives and the literature review. The first section of the survey for customers of US short staple yarn manufacturers was used to document company information. This section included the questions regarding size, origin of capital investment, product information, location, and whether or not the company buys yarn from US manufacturers. This section collected nominal data. In the second section, respondents, using a Likert scale, were also asked to rate the importance of key drivers that affected their decision to buy yarn from chosen manufacturers. 
TABle 1: Phase I: sample description.

\begin{tabular}{lclc}
\hline Product category & Company & Interviewee & Number of employees \\
\hline Fiber/yarn & A & Director of business development & 2,000 \\
Fiber/yarn & B & $\begin{array}{l}\text { Senior vice president in operations, America \& Strategic } \\
\text { Procurement }\end{array}$ & 3,200 \\
Fiber/yarn & C & Vice president in operations & 750 \\
Fiber/yarn & D & New business director & $\mathrm{n} / \mathrm{a}$ \\
Fiber/yarn & $\mathrm{E}$ & CEO/innovators & $>300$ \\
& & Senior vice president in manufacturing, & 1,600 \\
Fiber/yarn & $\mathrm{F}$ & manufacturing group vice president, & $\mathrm{n} / \mathrm{a}$ \\
Fiber/yarn & & Global Marketing manager, technical textiles division & 1,700 \\
Fiber/yarn & $\mathrm{G}$ & Manager of Six Sigma & $\mathrm{n} / \mathrm{a}$ \\
Fiber/yarn & $\mathrm{H}$ & Executive vice president & \\
\hline
\end{tabular}

$\mathrm{n} / \mathrm{a}$ : not available from the respondents.

After the questionnaire was field-tested with two industry experts to establish validity, the internal review board (IRB) approved the questionnaire.

3.2.3. Data Collection and Analysis. The sample of US yarn manufacturing customers was contacted by email. The survey invitation email included a link to the online survey.

The quantitative data was collected and grouped together. Mean scores of what the important key drivers that affect their decision to buy yarn from a chosen manufacturer (Phase II) are were calculated and directly compared to the mean scores of what, from a spinner's perspective, the key drivers that are important to their customers (Phase II) are.

\section{Results}

4.1. Phase I: Yarn Manufacturers' Sample. The goal of this phase of the research was to find out what US yarn manufacturers think are the important factors in maintaining a competitive yarn industry. The research sample consisted of 12 respondents from nine US textile companies of the fiber and yarn mills and auxiliary sectors. Table 1 provides information about the sample in Phase I, including product category, company identification, interviewee job positions, and size based on the number of employees. In general, the interviews followed the outline of the questionnaire. However, there were some deviations from the standard questions, which proved to be insightful and supplied additional factors that could be significant for consideration.

4.2. Phase I Results. In general, short lead time is thought by the spinners to be the most important driver influencing the customers' purchasing decision. Surprisingly, lower cost is thought by the spinners to be the least important driver. One executive commented that market proximity will become more important to customers because the freight cost tends to increase due to recent rises in oil prices. As long as there is the demand in the market, one respondent believes that he can sell yarn at a competitive price. Companies, which rated product quality as somewhat important, were asked further why product quality is not very important. The comment was "product quality is important, but it is not the most important." Overall, most of the respondents commented on the business strategy that "pull" or capability and willingness to produce products that can react to market is more important than "push" for the current market situation.

Most of the respondents strongly agreed that "optimization in management" improves quality, management decisions, productivity, profit, and opportunity of business. One of the respondents stated that it is not important to always have new technology to be able to produce the product that responds to customer needs. Sometimes old machinery can produce a product with certain desired properties. It was remarkable to see the disagreement on $\mathrm{R} \& \mathrm{D}$ issues from the interviews. One respondent indicated that while owning $\mathrm{R} \& \mathrm{D}$ is very important, using $\mathrm{R} \& \mathrm{D}$ as a major part in business strategy is not important for them.

In addition to the key drivers specifically asked about during the interviews, four additional drivers were discovered that need more attention in order to sustain the competitiveness of the US yarn manufacturing industry.

(i) Energy costs: US is competitive in the cost of electricity as long as the relationship between basic energy sources stays the same. When considering the cost to build a new plant in US and other countries, the cost of capital will be the same, for example, steel and cements for the building, but the difference depends on energy sources and standards to build the plant in different countries.

(ii) The limitation in sourcing fibers overseas: it is becoming harder to reliably source the fiber that customer wants, which is limited by trade compliance. An example given was the difficulty in sourcing black fiber for inclusion in T-shirt yarns. This is also important to the potential purchase of cotton fiber from sources other than the US, and this will impact the following concern. 
TABle 2: Phase II: sample description.

\begin{tabular}{|c|c|c|c|c|c|c|}
\hline \multirow[b]{2}{*}{ Company code } & \multirow[b]{2}{*}{ Area of work } & \multirow[b]{2}{*}{$\begin{array}{l}\text { Number of } \\
\text { employees }\end{array}$} & \multirow[b]{2}{*}{$\begin{array}{l}\text { The origin of } \\
\text { capital investments }\end{array}$} & \multicolumn{3}{|c|}{ Where company buys yarn from } \\
\hline & & & & US & $\begin{array}{l}\text { Other countries } \\
\text { (excluding US) }\end{array}$ & $\begin{array}{l}\text { Both US } \\
\text { and other } \\
\text { countries }\end{array}$ \\
\hline A1 & Purchasing & 150 or more & US capital & & & $\mathrm{X}$ \\
\hline B1 & Production & $0-49$ & Salvadoran capital & & & $\mathrm{X}$ \\
\hline $\mathrm{C} 1$ & Production & $100-149$ & Guatemalan capital & & & $\mathrm{X}$ \\
\hline D1 & Other sales' administration & 150 or more & Salvadoran capital & & & $\mathrm{X}$ \\
\hline $\mathrm{E} 1$ & Other full packages: costing, purchasing & 150 or more & Salvadoran capital & & & $\mathrm{X}$ \\
\hline $\mathrm{F} 1$ & Production & 150 or more & US Capital & & & $\mathrm{X}$ \\
\hline G1 & Purchasing, sourcing, and production & 150 or more & Salvadoran capital & & & $\mathrm{X}$ \\
\hline $\mathrm{H} 1$ & Production & 50-99 & Salvadoran capital & $\mathrm{X}$ & & \\
\hline I1 & Other planning area & 150 or more & Dominican capital & $\mathrm{X}$ & & \\
\hline $\mathrm{J} 1$ & Production & No response & Dominican capital & $\mathrm{X}$ & & \\
\hline $\mathrm{K} 1$ & Purchasing, other administration & $0-49$ & Costa Rican capital & & $\mathrm{X}$ & \\
\hline $\mathrm{L} 1$ & Production & 150 or more & Bolivian capital & & $\mathrm{X}$ & \\
\hline M1 & Sourcing, production & $0-49$ & US and Korean capital & & $\mathrm{X}$ & \\
\hline N1 & Production & 150 or more & Korean capital & & $\mathrm{X}$ & \\
\hline
\end{tabular}

(iii) Long-term availability of the right quality of cotton: particular concern was expressed in obtaining longterm commitments from cotton merchants over the availability of the fiber into future years. Because of the competition and potentially higher prices paid for cotton by international competitors, US spinners may have difficulty in having sufficient fiber supplies to meet customers' needs.

(iv) Farm bill: this was viewed as a great benefit, even though there was some unhappiness expressed over the fact that some of the benefits would be taxed. The finance from the farm bill could provide useful resources to maintain the technological advantages of the US spinners, since the funds must be used for equipment purchases.

4.3. Phase II: Yarn Customers' Sample. The goal of this phase of the research was to find out why weavers and knitters buy yarn from US manufacturers. The research sample consisted of 14 respondents from 14 companies in the textile and apparel industry, and these were located in DR-CAFTA region. The results represented the opinions of the yarn customers on the main drivers that influence their decision to purchase yarn from either the US or from other countries.

Table 2 provides information on the sample used in Phase II, including company codes, area of work of the respondents, number of employees, the origin of capital investments for each company, and whether the company buys yarn from the United States, other countries, or both. The sample respondents included people who work in purchasing, production, sourcing, administration, and planning from various countries in Central American areas. The sample represents seven companies that buy yarn from both US and other countries, three companies that buy yarn from US (excluding other countries), and four companies that buy yarn from other countries.
4.4. Phase II Results. In the case of purchasers of yarn from US manufacturers, product quality was rated as the most important driver in purchasing decision followed by tariff and trade benefits and short lead times in second and third places, respectively. Skill level of workforce was considered as the least important driver, which influenced yarn purchasing decision from US manufacturers.

In the case of purchasers of yarn from other countries (excluding US manufacturers), lower cost and short lead times were the most important drivers. Skill level of workforce was considered as the least important driver in the purchasing decision.

4.5. Results Summary: A Comparison of Phase I and Phase II. Further analysis was conducted regarding key drivers including perceived drivers versus actual drivers that influenced yarn purchasing decisions from US manufacturers. A radar chart was developed to compare the quantitative responses from both Phase I and Phase II. The chart graphically shows the size of the gaps among the nine drivers that influenced customers that purchased yarn compared to what US yarn manufacturers believe are the main reasons for purchasing yarn. This radar chart (Figure 4) illustrates that the largest gap exists in market proximity where the spinners think this driver is very important, whereas in reality the customer rates this driver as less important than other drivers.

This radar chart shows that five out of nine drivers (market proximity, short lead times, skill levels of workforce, customer relationship, and variety of product offers) from yarn manufacturers' judgments exceed the customers' expectation; product quality and tariff and trade benefits almost reach customers' expectation.

Lower cost is what yarn manufacturers have to work on to reach the customers' expectation. The spinners' views indicated that lower cost is the least important driver, since the price is a given and customers pay for quality. On the other hand, customers' views did not agree on these. Customers 


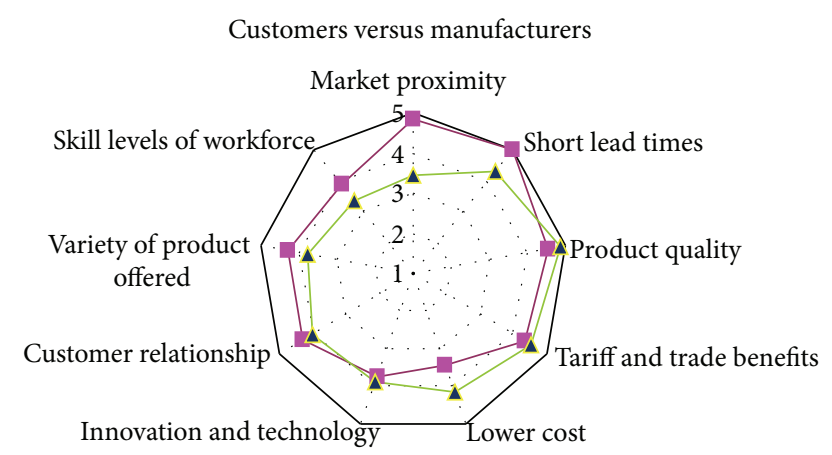

- Yarn manufacturers $(n=8)$

a- Yarn customers $(n=10)$

FIGURE 4: Radar chart shows a comparison of key drivers from what the spinners think to be important for customer versus what the customers actually think.

think that lower cost is a very important driver influencing yarn purchasing decisions.

4.6. Rethinking the Proposed Framework. After the data analysis of both the interviews and survey, it was clear that the simple visual (Figure 1) could not be used to illustrate the present dynamics in the short staple spinning industry. In summary, results lead to a conclusion that, instead of looking at each component individually, that is, "technology" or "management," it makes more sense to look at it as an integrated combination of both.

While "technology management" integration (Figure 2) may be purely a visual, it seems to better reflect the situation in the spinning industry as evidenced by the present research. From the interviews, it was gleaned that "technology" is now available to anyone who has sufficient finances. Thus, while in the past the US was regarded as being much more technologically advanced compared to China and India, this is no longer the truth. Respondents stated that these "developing countries" are actually investing significantly more in newer spinning technology than the United States.

The major advantage which the US yarn manufacturers claimed is having the ability to "optimize the use of new technology." This is essentially how to use "technology management" approach. This process starts with the following:

(i) selecting fiber for particular "high tech" machines which is based on meeting the ultimate requirements of the yarn purchasers,

(ii) optimizing the processing of fiber to not only produce a high quality yarn but also do this economically,

(iii) ensuring that there is an adequate current and future market for the yarn,

(iv) servicing the customers by creating customer relations (knowing what they want and how they want it).

It should therefore be evident that, in the present spinning enterprise, technology and management are so interwoven and interdependent; it is extremely difficult to absolutely

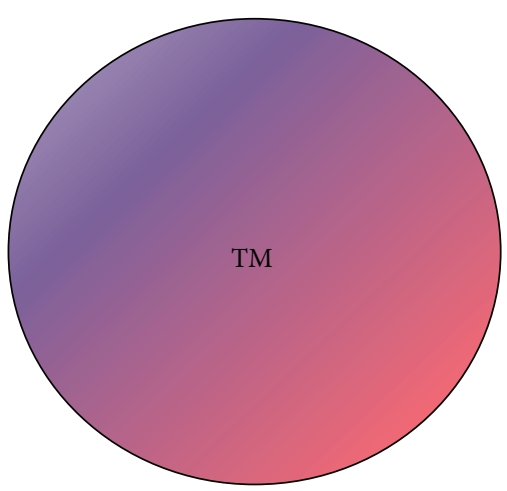

FIGURE 5: New "technology management” integrated system.

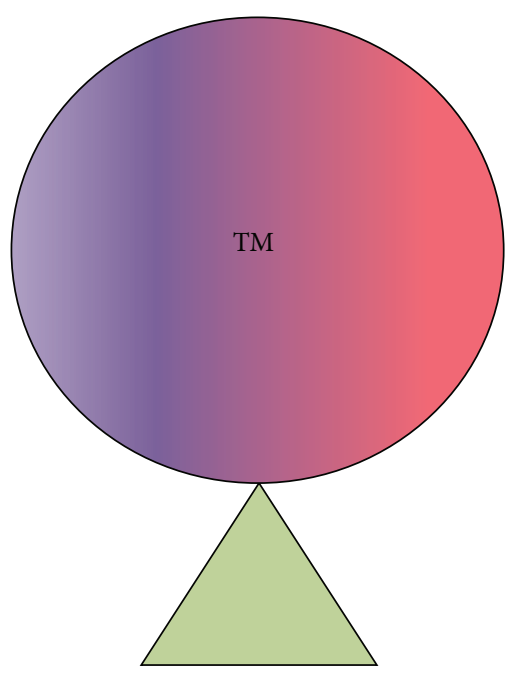

FIGURE 6: The balance of new "technology management" integrated system.

define many drivers as either technology or management. Therefore, the integrated, diffuse visual (Figure 5) is considered more appropriate than the initial proposed visual (Figure 2).

However, in the current climate of rapid changes in most aspects of the global economics, it is important to consider the new "technology management" integrated system as a carefully balanced sphere sitting at top of a pivot, representing both internal and external pressures that have a direct impact on the competitiveness of the US yarn manufacturing industry (Figure 6). Examples include energy costs, US trade policy, technology, and raw material costs. This technology management fusion has a combination of product, market, and service components. Any small changes caused by internal or external pressures could destabilize the system. In other words, there is much more volatility to sustaining a company than ten years ago.

4.7. Limitations of the Study. For this particular study, only "cotton yarn" was included which is a combination of 300 and 301 series in the US textile and apparel category. Even though this study only included one specific industry, the study's 
methodology can be replicated with different industries efficiently. Due to the limited sample size, both the survey and interview results can only be generalized to those companies that participated in the study and not the entire short staple yarn manufacturing industry.

\section{Conclusions}

The conclusions are based on the original research questions and while there are some interdependence of the responses and results, it was believed to be appropriate to discuss these as separate items.

5.1. What Are the US Short Staple Yarn Manufacturing Competitive Advantages in relation to Other Countries through Selected Regions and Countries? In the yarn purchasers' opinion, US manufacturers have competitive advantages over other countries because of these key drivers: skill level of workforce, variety of products offered, customer relationships, innovation and technology, and product quality. In order to keep these competitive advantages, "technology" and "management" strategies should be implemented. For example, innovation and technology can be created by using the "niche" approach in product differentiation.

US manufacturers should be aware and focus on the perceived key drivers which influence yarn purchasing decisions from yarn customers. This is demonstrated by the fact that yarn manufactures perceived market proximity as the most important driver and low cost as the least important driver for their customers. When in reality, the yarn customers perceived these drivers as opposite.

Government policy makers should be encouraged, since tariff and trade benefits are considered very important by both yarn spinners and yarn customers. Additional competitive advantages include US energy costs when compared to other countries, the limitation in sourcing fiber overseas, the longterm availability of the right quality of cotton, and the US farm bill.

5.2. Can Technology and Management Strategies Be Optimally Integrated to Sustain a US Short Staple Yarn Manufacturing Industry? Yes, the US yarn manufacturing industry can be sustained with the optimal integration of technology and management. The concept of "technology management" refuted the conceptual model in the literature review, which separates "technology" and "management." From Phase I discussions, it is evident that most US spinners think "technology" is less important than "management" in order to sustain a US yarn manufacturing industry in global competition. Their reasons are that technology is available to anyone who has the money; however, "managing the technology" and "managing the enterprise" are what is needed to make the technology successful. As time goes on, separating management and technology is becoming more difficult. For example, the use of cotton data (EFS) was considered "management," while the use of software to control the subunit transactions in the company was considered "technology blended with management."
In summary, there was universal agreement that while both technology and management are important, it is the new "technology management" integrated system that is the key to staying competitive. Thus, the skill of optimally using the latest equipment, matched with fiber knowledge, in order to yield the best yarn (quality and cost) demonstrates a critical blend of management and technology know-how.

\section{Conflict of Interests}

The authors declare that there is no conflict of interests regarding the publication of this paper.

\section{References}

[1] J. Phillips, "Consumer product recalls prompt product visibility questions," Textile World, 2007, http://www.textileworld .com/News.htm?CD=3847\&ID=13599.

[2] M. H. Best, The New Competitive Advantage: The Renewal of American Industry, Oxford University Press, New York, NY, USA, 2001.

[3] H. Chesbrough, Business Models: How to Thrive in the New Innovation Landscape, Harvard Business School Press, Boston, Mass, USA, 2006.

[4] D. Mitchell and C. Cole, "The ultimate competitive advantage of continuing business model innovation," Journal of Business Strategy, vol. 24, no. 5, pp. 15-21, 2003.

[5] BNET Business Network, "BNET business dictionary," 2008, http://www.webcitation.org/getfile?fileid=5be050e5d3888039e5d99c9aa2c2f40209390955.

[6] Plunkett's Research, "Apparel and textiles industry trends," 2004, http://www.plunkettresearch.com/.

[7] Kurt Salmon Associates (KSA), Vision and Perspective of Consumer Behavior and Trends in Clothing, Deutscher Fachverlag GmnH, Frankfurt, Germany, 2004.

[8] KSA, "Trends in consumer's behavior and the global clothing market," Textile Outlook International, vol. 118, pp. 120-150, 2005.

[9] P. Dicken, Global Shift: Reshaping the Global Economic Map in the 21st Century, The Guilford Press, New York, NY, USA, 4th edition, 2003.

[10] O. Sabanci, "Meeting the challenge of global competition," International Fiber Journal, vol. 20, no. 4, pp. 4-6, 2005.

[11] C. Freeman, "The "national system of innovation" in historical perspective: technology, globalization and economic performance," Cambridge Journal of Economics, vol. 19, no. 1, pp. 5-24, 1995.

[12] P. H. Dinsdale, "Developing investments in textiles in emerging markets the search for quality projects," in Proceedings of the Textile Institute 83rd World Conference (TIWC '04), vol. 3, pp. 1193-1199, Shanghai China, May 2004.

[13] L. Abbott, Quality and Competition, Columbia University Press, New York, NY, USA, 1955.

[14] H. L. Gilmore, "Product conformance cost," Quality Progress, vol. 7, no. 15, pp. 16-19, 1974.

[15] J. M. Juran and F. M. Gryna, Juran's Quality Control Handbook, McGraw-Hill, Hightstown, NJ, USA, 4th edition, 1988.

[16] A. Parasuraman, V. A. Zeithaml, and L. L. Berry, "A conceptual model of service quality and its implications for future research," Journal of Retailing, vol. 69, no. 1, pp. 140-147, 1993. 
[17] S. A. Zahra and J. G. Covin, "Business strategy, technology policy and firm performance," Strategic Management Journal, vol. 14, no. 6, pp. 451-478, 2003.

[18] R. K. Yin, Case Study Research: Design and Methods, Sage, Thousand Oaks, Calif, USA, 1994.

[19] E. D. Parrish, Niche market opportunities in the global marketplace [Ph.D. dissertation], North Carolina State University, Raleigh, NC, USA, 2003. 

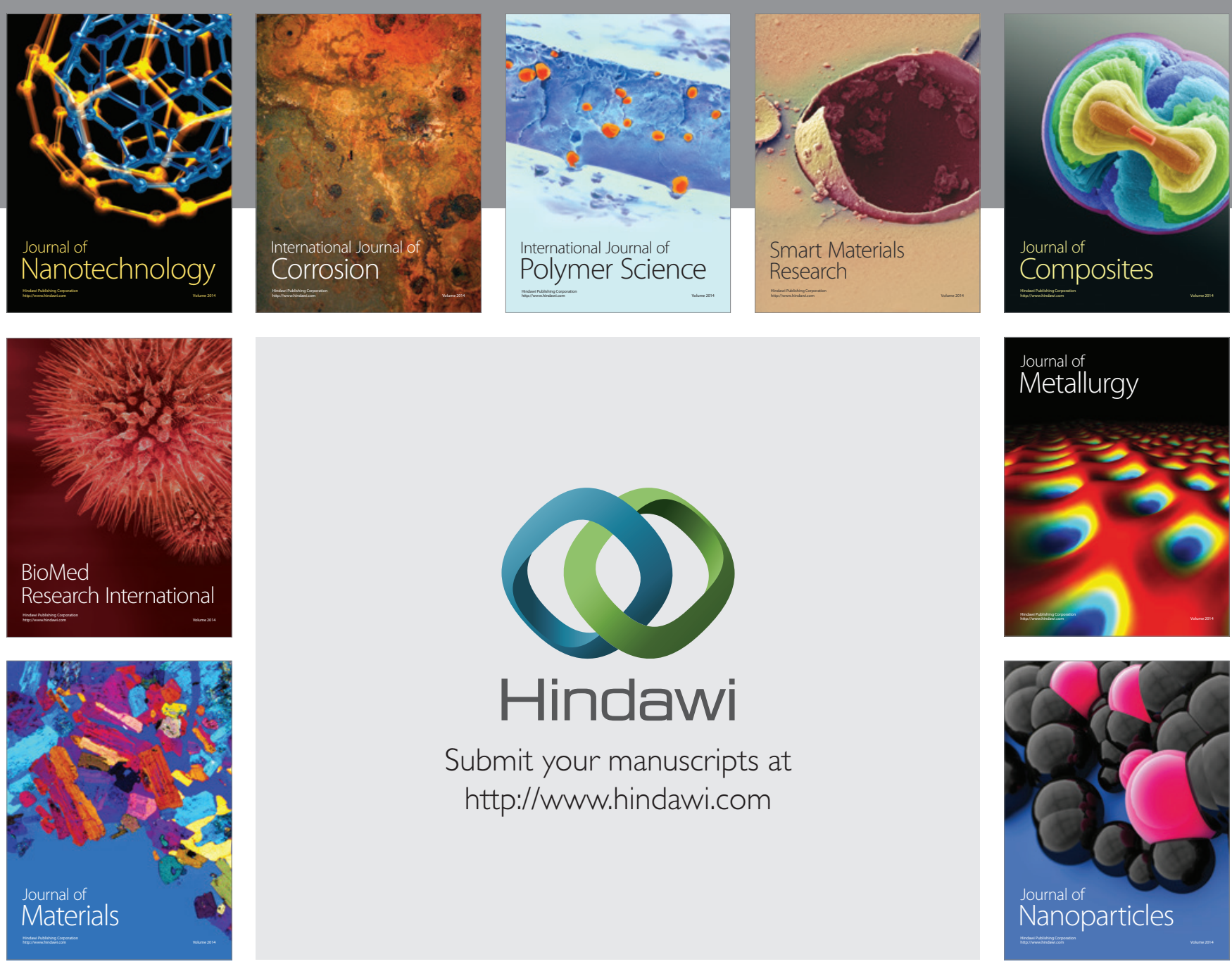

Submit your manuscripts at http://www.hindawi.com
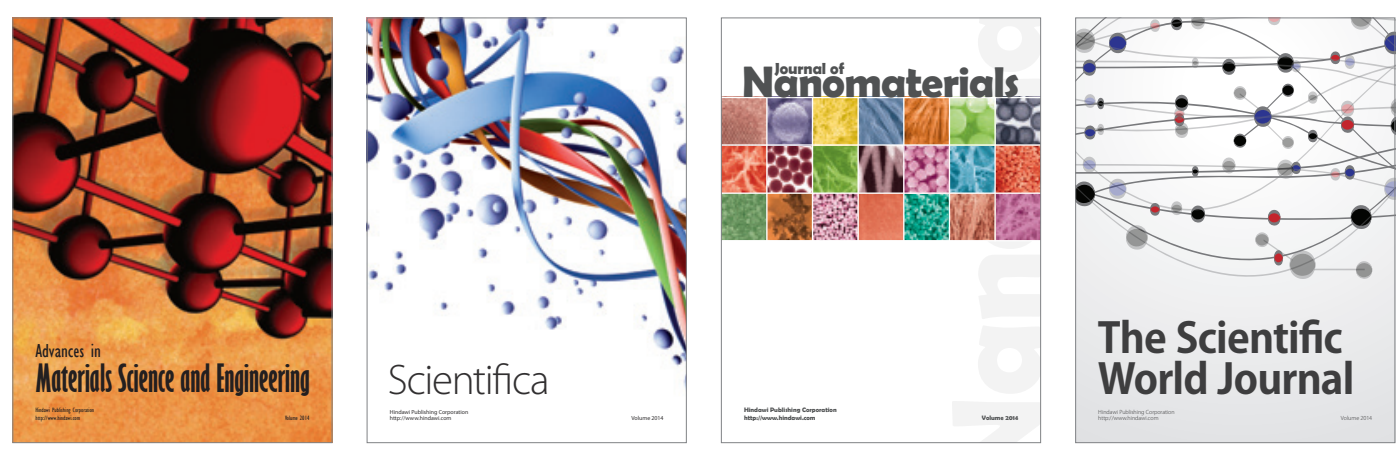

\section{The Scientific World Journal}
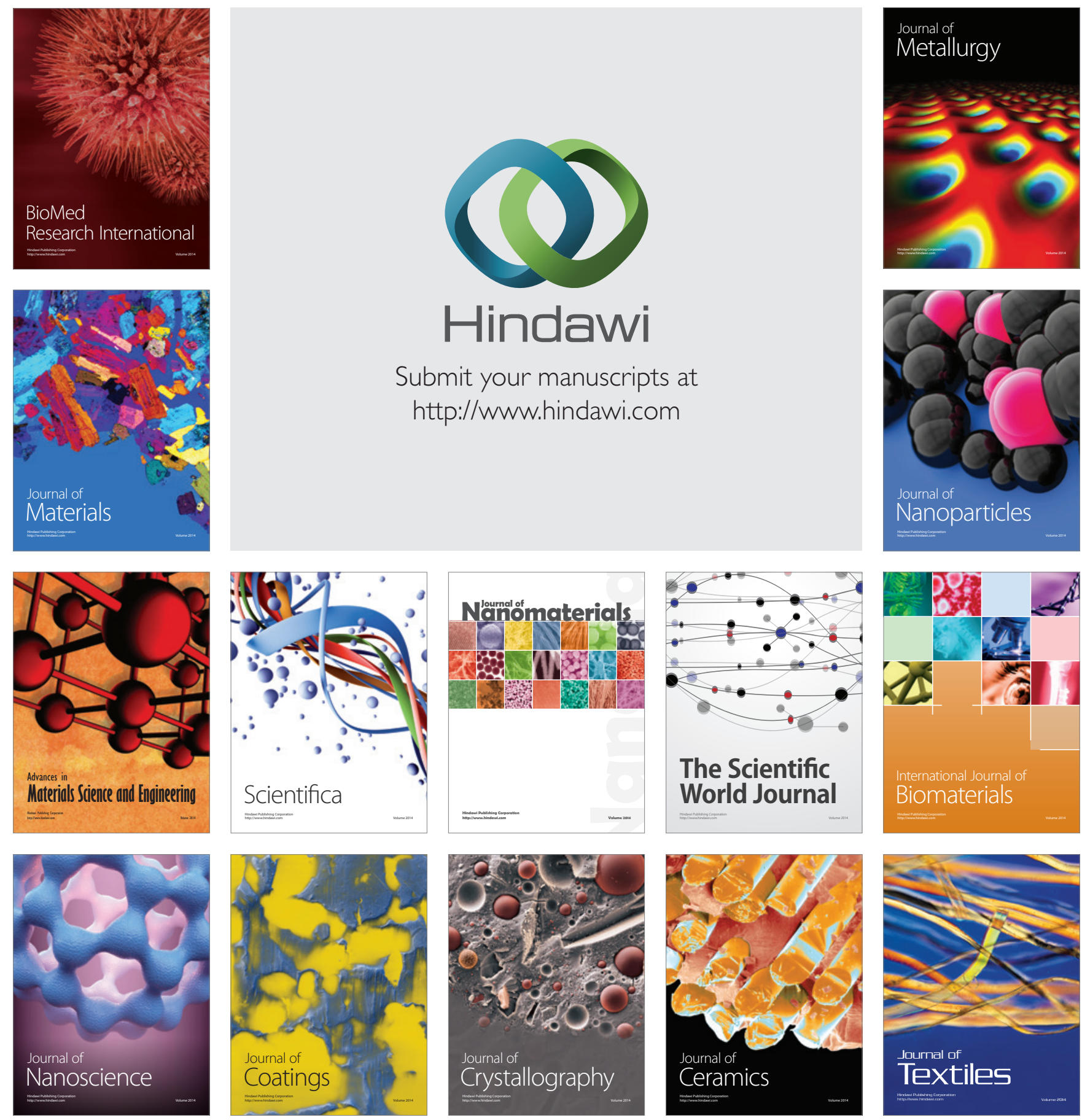